\title{
Prevalent use of herbs for reduction of labour duration in Mwanza, Tanzania: are obstetricians aware?
}

\author{
HARUNA DIKA ${ }^{1 *}$, MAUKI DISMAS ${ }^{2,3}$, SHABANI IDDI ${ }^{1}$ and RICHARD RUMANYIKA ${ }^{2,4}$ \\ ${ }^{1}$ Department of Physiology, Weill Bugando School of Medicine, Catholic University of Health and Allied \\ Sciences, P. O. Box 1464, Mwanza, Tanzania \\ ${ }^{2}$ Bugando Medical Centre, Mwanza, Tanzania \\ ${ }^{3}$ Archibishop Antony Mayalla School of Nursing, Catholic University of Health and Allied Sciences, Mwanza, \\ Tanzania \\ ${ }^{4}$ Department of Obstetrics and Gynaecology, Weill Bugando School of Medicine, Catholic university of Health \\ and Allied Sciences, Mwanza, Tanzania
}

\begin{abstract}
Background: The use of herbs during pregnancy and labour is rapidly increasing because the herbs are considered to be natural and therefore free of risks. Despite of this perception, a number of herbs have been reported to have negative effects to the new-borns and the mothers. Therefore, this study aimed to determine the prevalence and factors associated with the use of herbs during labour among women in Mwanza, Tanzania.

Methods: The study involved women who delivered at Bugando Medical Centre and Sekou Toure Hospital in Mwanza, north-western Tanzania. Data were collected using questionnaires. Comparison of prevalence of herb use by various factors was done.

Results: A total of 178 women were involved in the study. The mean age of participants was $26.6 \pm 5.4$ years. The prevalence of herb use was found to be $23.0 \%$. The use of herbs was significantly associated with marital status $(p=0.011)$ and the use during previous deliveries $(p=0.000)$.

Conclusion: The study findings signify that, about a quarter of women in Mwanza use herbs during childbirth and the use encourages recurrent use of these herbs in subsequent pregnancies. A large scale survey is recommended to determine the extent of use of traditional herbs during pregnancy and childbirth countrywide. Studies to determine the toxic profile of the herbs which are used are also needed so as to address the matter to the community.
\end{abstract}

Keywords: herbs, use, pregnant women, delivery, labour, Tanzania

\section{Introduction}

Many women worldwide use various traditional herbs during pregnancy and/or labour and the use is rapidly increasing (Eisenberg et al., 1998; Ernst, 2002; Ramasubramaniam et al., 2015). Studies in developed countries have reported that significant number of pregnant women use herbal remedies for induction of labour, although there is no compelling proof of their efficacy (Jones \& Lawson, 1998; Ernst et al., 2001). The practice is also common across African and Asian countries. In South Africa for instance, dozens of herbal medicines from different plants are used by South African women during or before delivery (Veale et al., 1992). In India, pregnant women frequently use kasayam (a mixture of ginger, jiggery, cumin, anise and black coriander powder) during labour (Van Hollen, 2003). Health surveys in Bushenyi district in Uganda revealed that over $80 \%$ of women use herbs during labour where by 75 different traditional herbs were reported to be used for inducing labour (Kamatenesi-Mugisha \&Oryem-Origa, 2007).

Various herbal remedies are used during the prenatal period to prepare the uterus and cervix for childbirth and ease pain during labour and enhance endurance during delivery (Tournaire \& Theau-Yonneau, 2007). Some communities have been reported to use herbs for purpose of accelerating labour to avoid augmentation in hospital (Attah et al., 2012; IbáñezCuevas et al., 2015).

\footnotetext{
* *Correspondence E-mail: hdika2001@yahoo.co.uk
} 
The use of herbs during labour may have negative effects to the new-borns and the mothers because several of the traditional herbs are poisonous and therefore pose danger to the mothers and new-borns (Veale et al., 1992). Blue and black cohosh which are used during pregnancy and labour are known to cause myocardial infarction (Jones \&Lawson, 1998), seizures and kidney damage (Gunn \& Wright, 1996). Other herbs which are used during pregnancy and labour may cause hypertension (Nambiar et al., 1999) and liver damage (But et al., 1996). Use of castor oil during pregnancy or labour has been associated with passage of meconium and respiratory distress (Mitri et al., 1987). The use of Montana tomentosa during labour has also been linked to new-borns cardiorespiratory depression and poor APGAR score (Ernst, 2002). The use of herbs with oxytocic effects may result in uterine hyperstimulation, with adverse effects such as foetal asphyxia and uterine rupture (Jonsson et al., 2008). Despite of the unknown pharmacology and toxicity of the herbs which are used, pregnant women frequently use them because they are often perceived as being 'natural and therefore free of risks' (Chez \& Jonas, 1997).

Several traditional herbs used during labour are poisonous and therefore dangerous to the mothers and new-borns (Veale et al., 1992). This information needs to be known to the health workers and community at large. There are unofficial reports of unstructured use of herbs before and during labour, where women are given herbs at home and then delay to go to health facilities for delivery. However, the types of herbs used and the extent of their use before and/or during labour among pregnant women in many parts of Tanzania are largely unknown. Generally, there is limited data about prevalence of use of herbs during delivery in Tanzania, type of herbs used and factors associated with their use. Therefore, this study aimed to determine the prevalence and factors associated with the use of herbs during labour among women in Mwanza City, Tanzania.

\section{Material and Methods}

\section{Study setting and subjects}

The study was conducted at Bugando Medical Centre (BMC) and Sekou Toure Hospital in Mwanza, Tanzania. BMC is a consultant referral zonal Hospital for Lake Victoria Zone regions. Sekou Toure Hospital is the regional referral hospital located in Nyamagana District within Mwanza City, Tanzania.

The study involved women who delivered at BMC and Sekou Toure hospital. Sample size was calculated by using the formula by Kish (1965), $N=Z^{2} p[1-p] / d^{2}$, where $N=$ sample size, $Z=$ confidence interval score (1.96), $p=$ estimated prevalence and $d=$ standard error (5\%). Using the prevalence of herb use among pregnant women with access to healthcare (12\%) obtained from a study done in Nairobi (Mothupi et al., 2014), gave the minimum sample size of $162\left(N=Z^{2} P[1-P] / d^{2}\right.$, $\left.\mathrm{N}=1.96^{2 *} 0.12(1-0.12) / 0.05^{2}=162\right)$. Mothers delivered by elective caesarean section and seriously sick mothers were excluded from this study. A consecutive sampling procedure was used to include subjects that met the selection criteria.

\section{Data collection}

Using a pretested structured questionnaire subjects were interviewed after delivery and before they were discharged from hospital. The interview was in Kiswahili. However, in the two instances, the interview was in Kisukuma language because the participants could not fluently speak Kiswahili. Interview inquired about socio-demographic characteristics and the use of herbs during labour. Subjects were asked if they used herbs during index delivery, type of herbs they used, reasons for use as well as the use during previous deliveries for those who had previously delivered. 


\section{Data analysis}

Data were analysed using STATA software version 11. Categorical data were cleaned, edited and coded. Numerical data and coded categorical data were entered into MS Excel sheet and then exported into STATA. Categorical variables were summarized into frequencies and percentages. Variation of prevalence of use of herbs by various factors was done by either Chi-square tests or Fisher's exact test depending on appropriateness. Statistical significance level was fixed at twotailed $p$-value of 0.05 .

\section{Ethical considerations}

Ethical clearance was sought and provided by the joint Catholic University of Health and Allied Sciences and BMC Research Ethics and Review Committee. Permissions to collect data at Bugando Medical Centre and Sekou Toure hospital were granted by the respective hospital administration.

\section{Results}

\section{Characteristics of study subjects}

A total of 178 women were involved in the study. The mean age of participants was $26.6 \pm 5.4$ years. The study enrolled women from different tribes and they had varying educational levels and income. Most of the women who participated in this study were delivered for the first or second time with only one third of them being delivering for three or more times. Majority (92.1\%) of the women had spontaneous vaginal delivery while only $7.9 \%$ had delivered by unplanned caesarean section as emergency.

\section{Use of Herbs during labour}

Forty-one (23.0\%) of 178 study participants reported to use herbs during the index delivery (Table 1). Twenty-three $(56.1 \%)$ of the subjects who used herbs, ingested them shortly before onset of active labour while 18 (43.9\%) used after onset of active labour. Most of the herbs used during delivery could not be identified by generic names but by local names. Out of 41 subjects who used herbs, 28 (68.3\%) used for the purpose of shortening duration of labour, 15 (36.6\%) avoiding caesarean section while $7(17.1 \%)$ for the easing pain and $2(4.9 \%)$ gave other different reasons, namely strengthening the baby and increasing milk. The herbs which were reported to be used included ginger (Zingier officinale), onions (Allium cepa) and neem (Azadirachta indica). Traditional herbs which were only identified by local names were ekakwingili, matola, makarekambona, akabindizi, ekinunulizi, enyabashumi, binzari nyembamba, mgagani, mshana and msuana. Among those reported to use herbs, $12(29.3 \%)$ reported to use herbs which could not be identified by their generic or local names as the users did not know what they were given and ingested.

Table 1: Prevalence of use of herbs by age

\begin{tabular}{llll}
\hline Age (in years) & Number of women & Frequency of herb use & Percentage \\
\hline$<20$ & 19 & 3 & 15.8 \\
$20-24$ & 43 & 12 & 27.9 \\
$25-29$ & 66 & 18 & 27.3 \\
$30-34$ & 35 & 3 & 8.6 \\
$>34$ & 15 & 5 & 33.3 \\
Total & 178 & 41 & 23.0 \\
\hline
\end{tabular}

\section{Factors associated with the use of herbs during labour}

There was no significant difference $(p=0.153)$ in the prevalence of herb use between participants of varying age groups (Table 1). Most participants, who used herbs, reported that, they were 
advised by their mothers (39\%) or sisters (19.5\%) (Figure 1). Fifteen (36.6\%) of the women who used herbs during labour were delivering for the first time, and $26(63.4 \%)$ were delivering for the second time or more. There was no significant $(p=0.811)$ difference in the prevalence of use of traditional herbs between women of different parities. Among the participants, seven tribes were identified. These were Sukuma (73), Haya (25), Kurya (5), Nyambo (6), Kerewe (7), Jita (5), Nyamwezi (8) and others (49). Prevalence of herb use did not significantly $(p=0.305)$ differ between women of various tribes. Women who stayed near (within $5 \mathrm{~km}$ ) to hospitals tended to use herbs relatively more (24.2\%) than those who lived far (more than $20 \mathrm{~km}$ ) from hospitals (14.3 $\%)$, but the difference was not statistically significant $(p=0.431)$.

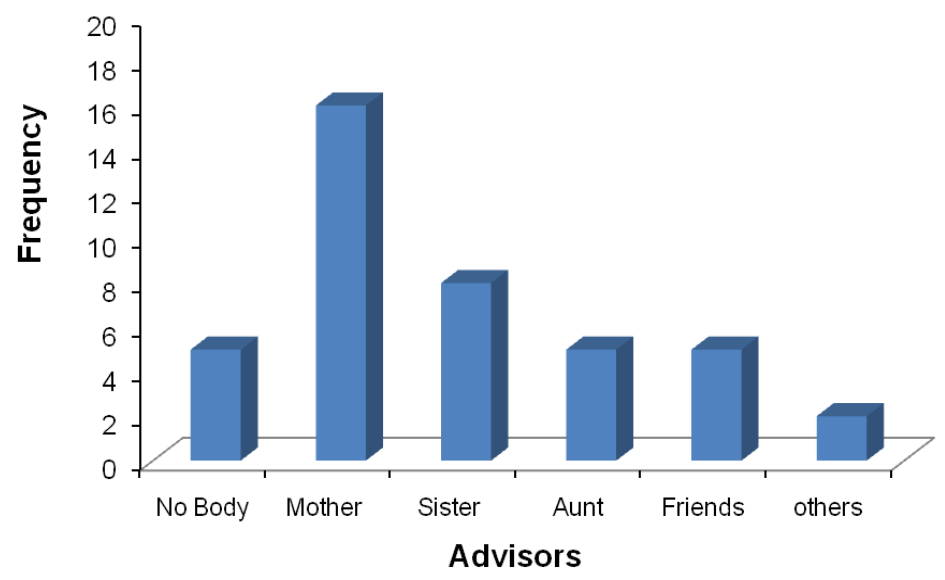

Figure 1: People who advised the participants to use herbs

History of use of herbs during previous deliveries was an indicator for recurrent use of herbs in subsequent pregnancies as we observed that, out of 26 women who used herbs and were delivering for the second or more time, 21 (80.8\%) had used herbs during previous deliveries compared to only $5 / 106(4.7 \%)$ who did not use herbs during previous deliveries $(p=0.003)$. The rate of herbs use was significantly $(p=0.013)$ higher $(42.9 \%)$ among women with some knowledge about delayed labour onset and prolonged labour compared to those who completely did not know neither delayed labour onset nor prolonged labour (19.2\%). 
A

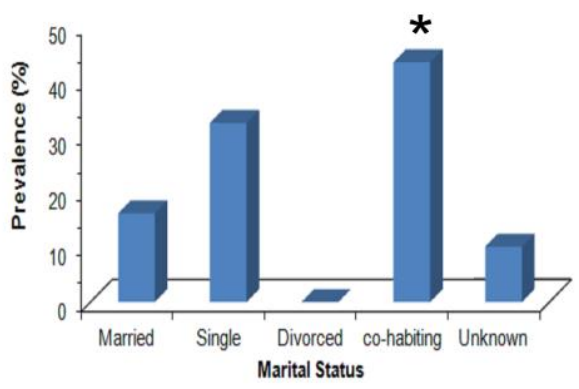

C

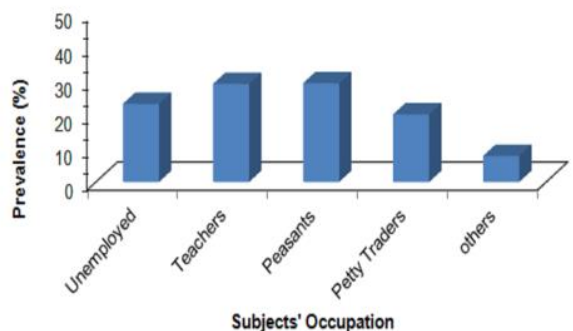

B
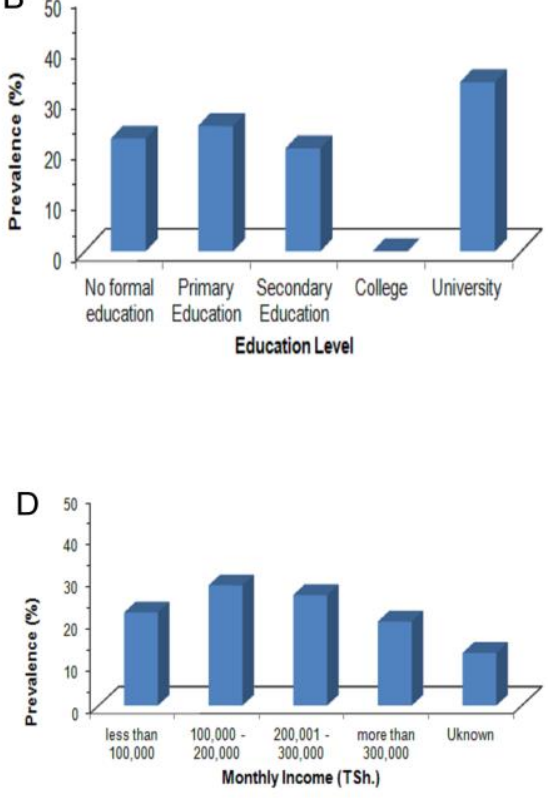

Figure 2: Prevalence of herb use by marital status (A), education level (B), occupation (C) and monthly income (D) Key: * indicates p value $<0.05$.

The prevalence of herb use significantly $(p=0.002)$ varied by marital status of the subjects (Figure $2 A$ ). Co-habiting women had a significantly higher prevalence of herb use compared to other women (panel $A)$. Decision to use herbs during delivery was not influenced by subject's level of education $(p=1.000)$ (Figure $2 B)$. Though there was a tendency for more peasants and teachers to use herbs compared to other groups, the difference was not statistically significant $(p=0.300)$ (Figure $2 C$ ). Likewise, subject's monthly income did not predict $(p=0.691)$ the use or non-use of herbs during labour (Figure 2D).

\section{Discussion}

The observed prevalence of herb use during delivery concurs with previous information that, despite of expertise practices of use of oxytocin or artificial rupture of membranes for inducing or accelerating labour, a significant proportion of women worldwide use herbal medicines for the same purpose among other reasons (Ernst, 2002; Ramasubramaniam et al., 2015; Veale et al., 1992). For example, in the United States some pregnant women have been reported to use blue cohosh to promote uterine contractions (Jones \& Lawson, 1998). Other herbs such as baobab tree are used during labour to prevent and treat postpartum haemorrhage as well as to expel a retained placenta (Bij de Vaate et al., 2002). However, the prevalence observed in the current study is far lower compared to those (50-88\%) reported from other African countries (Veale et al., 1992; Kamatenesi-Mugisha \& Oryem-Origa, 2007; Mureyu et al., 2012). The low prevalence of herb use in the present study as opposed to higher prevalence in other countries may be due to the reasons for use. While most of the women who used herbs in our study had an intention of shortening duration of labour, most women in developed countries use herbal remedies as the principal method of managing pain and enhancing endurance during delivery (Tournaire \& TheauYonneau, 2007).

Although in the current study, tribe was not a predictive factor in the use of herbs, the use of herbs is likely to be affected by culture. In a study in Zambia, the use of medicinal herbs was believed to expedite the delivery process, to assist in difficult deliveries and for body cleansing following a miscarriage (M'soka \& Mabuza, 2015). High prevalent use of herbal medicines among African rural population is associated with a lack of access to public healthcare (WHO, 2008), as well as with social and cultural influences (Sindiga, 1995). Contrary to most 
previous studies which reported that, pregnant women use herbal medicines under recommendation of health care workers (Einarson et al., 1999; McFarlin et al., 1999; Allaire et al., 2000), in this study most of the women used herbs following advice from their mothers, sisters or other relatives. Different from previous knowledge that the use of herbal medicine is associated with low education levels (Addo, 2007; Mothupi, 2014), the current study did not find any association between education and herbs use. Perceived efficacy and beliefs about safety are likely causes of lack of association between herbal use and education level in the current study as these factors are likely to affect both educated and illiterate people equally.

While a significant number of the herbs used were unidentified similar to previous studies (Rahman et al., 2008), only few herbs were mentioned to be used as opposed to dozens of different herbs which have been reported in other African countries (Veale et al., 1992; Kamatenesi-Mugisha \& Oryem-Origa, 2007). Over 57 different plants herbal remedies are known to be used by South African women (Veale et al., 1992) and over 75 herbs are used by Ugandan women to induce labour (Veale et al., 2007; Kamatenesi-Mugisha \& Oryem-Origa, 2007). A study in South Africa included the herbs which were used during both pregnancy and childbirth while we focused on the herbs which were used shortly before onset of active labour or during active labour. The herbs reported to be used during delivery in the current study are different from those used elsewhere. For instance, studies in India described self-administration of kasayams (mixtures of ginger, jaggery, cumin, anise, and black coriander seeds) as herbs use during labour (Van Hollen, 2003). In the United States, some pregnant women use blue cohosh to promote uterine contractions (Jones \& Lawson, 1998). In Malaysia, coconut oil is commonly used because it is believed to facilitate labour (Rahman et al., 2008). Some South African women use comfrey roots to induce labour naturally and raspberry leaf tea during delivery (Veale et al., 1998). This difference in types of herbs used in different countries could be due to local availability and cultural differences.

The findings of our study have some limitations. The hospital setting of this study could have led to underestimation of the prevalence of herbs use due to un-disclosure of some women who might have used herbs. Another limitation of this study was the failure to identify botanic names of most herbs which were used.

The study has provided information that there is significant number of women who use herbs during childbirth in Tanzania. While the chemical nature of the herbs and their toxic effects to the mother and foetus are unknown, the use of herbs during previous delivery encourages recurrent use of these herbs in subsequent pregnancies. Therefore, health education about the effects of the herbs during pregnancy should be provided to women starting during early antenatal visits. A large scale survey to determine the extent of use of traditional herbs during pregnancy and labour is recommended. Further studies are required to determine the safety of the herbs used and their effect on labour duration.

\section{Acknowledgements}

We acknowledge nurses and doctors in the labour wards of BMC and Sekou-Toure hospital for their support during data collection.

\section{Declaration of Interest}

There is no conflict of interest that could be perceived as prejudicing the impartiality of the research reported.

\section{References}


Addo, V. (2007) Herbal medicines: socio-demographic characteristics and pattern of use by patients in a tertiary obstetrics and gynaecology unit. Journal of Science and Technology (Ghana) 27: 149-155.

Allaire, A. D., Moos, M.-K. \& Wells, S. R. (2000) Complementary and Alternative Medicine in Pregnancy: A Survey of North Carolina Certified Nurse-Midwives. Obstetrics \& Gynecology, 95: 19-23.

Attah, A.F., O'Brien, M., Koehbach, J., Sonibare, M.A>, Moody, J.O., Smith, T.J. \& Gruber, C.W. (2012) Uterine contractility of plants used to facilitate childbirth in Nigerian ethnomedicine. Journal of Ethnopharmacology 143: 377-382

Bij De Vaate, A., Coleman, R., Manneh, H. \& Walraven, G. (2002) Knowledge, attitudes and practices of trained traditional birth attendants in the Gambia in the prevention, recognition and management of postpartum haemorrhage. Midwifery 18: 3-11.

But, P., Tomlinson, B. \& Lee, K.-L. (1996) Hepatitis related to the Chinese medicine Shou-wu-pian manufactured from Polygonum multiflorum. Veterinary and Human Toxicology 38: 280282.

Chez, R. A. \& Jonas, W. B. (1997) Complementary and alternative medicine. Part I: clinical studies in obstetrics. Obstetrical \& Gynecological Survey 52: 704-708.

Einarson, A., Lawrimore, T., Brand, P. E. A., Gallo, M., Rotatone, C. \& Koren, G. (1999) Attitudes and practices of physicians and naturopaths toward herbal products, including use during pregnancy and lactation. Canadian Journal of Clinical Pharmacology 7: 45-49.

Eisenberg, D.M., Davis, R.B., Ettner, S.L., Appel, S., Wilkey, S., Van Rompay, M. \& Kessler, R.C. (1998) Trends in alternative medicine use in the United States, 1990-1997: results of a follow-up national survey. JAMA 280: 1569-1575.

Ernst, E. (2002) Herbal medicinal products during pregnancy: are they safe? BJOG: An International Journal of Obstetrics \& Gynaecology 109: 227-235.

Ernst, E., Pittler, M.H. \& Wider, B. (2001) The Desktop Guide to Complementary and Alternative Medicine: an Evidence-Based Approach. Mosby Hartcourt.

Gunn, T. \& Wright, I. (1996) The use of black and blue cohosh in labour. New Zealand Medical Journal 109: 410.

Ibáñez-Cuevas, M., Heredia-Pi, I.B., Meneses-Navarro, S., Pelcastre-Villafuerte, B. \& González-Block, M.A. (2015) Labor and delivery service use: indigenous women's preference and the health sector response in the Chiapas Highlands of Mexico. International Journal for Equity in Health 14:156

Jones, T.K. \& Lawson, B.M. (1998) Profound neonatal congestive heart failure caused by maternal consumption of blue cohosh herbal medication. Journal of Pediatrics 132: 550-552.

Jonsson, M., Nordén-Lindeberg, S., Östlund, I. \& Hanson, U. (2008) Acidemia at birth, related to obstetric characteristics and to oxytocin use, during the last two hours of labor. Acta Obstetricia et Gynecologica Scandinavica 87: 745-750.

Kamatenesi-Mugisha, M. \& Oryem-Origa, H. (2007) Medicinal plants used to induce labour during childbirth in western Uganda. Journal of Ethnopharmacology 109: 1-9.

Kish, L (1965) Survey Sampling, New York: Wiley

Mcfarlin, B.L., Gibson, M.H., O'rear, J. \& Harman, P. (1999) A national survey of herbal preparation use by nurse-midwives for labor stimulation. Journal of Nurse-Midwifery 44: 205-216.

Mitri, F., Hofmeyr, G. \& Van Gelderen, C. (1987) Meconium during labour--self-medication and other associations. South African medical Journal 71: 431-433.

Mothupi, M.C. (2014) Use of herbal medicine during pregnancy among women with access to public healthcare in Nairobi, Kenya: a cross-sectional survey. BMC Complementary and Alternative Medicine 14: 1.

M'soka, N.C., Mabuza, L.H. \& Pretorius, D. (2015) Cultural and health beliefs of pregnant women in Zambia regarding pregnancy and child birth. Curations 38: doi:10.4102 
Mureyi, D.D., Monera, T.G. \& Maponga, C.C. (2012) Prevalence and patterns of prenatal use of traditional medicine among women at selected harare clinics: a cross-sectional study. BMC Complementary and Alternative Medicine 12: 1.

Nambiar, S., Schwartz, R.H. \& Constantino, A. (1999) Hypertension in mother and baby linked to ingestion of Chinese herbal medicine. Western Journal of Medicine 171: 152.

Rahman, A.A., Sulaiman, S.A., Ahmad, Z., Daud, W.N. \& Hamid, A.M. (2008) Prevalence and pattern of use of herbal medicines during pregnancy in Tumpat district, Kelantan. Malaysian Journal of Medical Sciences 15: 40.

Ramasubramaniam, S., Renganathan, L., Vijayalakshmi, G. \& Mallo-Banatao, M. V. (2015) Use of herbal preparations among parturient women: Is there enough evidence-A review of literature. International Journal of Herbal Medicine 2: 20-26.

Sindiga, I. (1995) Traditional medicine in Africa: An introduction. Traditional Medicine in Africa, Nairobi, East African Educational Publishers 1-15.

Tournaire, M. \& Theau-Yonneau, A. (2007) Complementary and alternative approaches to pain relief during labor. Evidence-based Complementary and Alternative Medicine 4: 409-417.

Van Hollen, C. (2003) Invoking vali: painful technologies of modern birth in south India. Medical Anthropology Quarterly 49-77.

Veale, D., Furman, K. \& Oliver, D. (1992) South African traditional herbal medicines used during pregnancy and childbirth. Journal of Ethnopharmacology 36: 185-191.

Veale, D., Havlik, I., Katsoulis, L., Kaido, T., Arangies, N., Olive, D., Dekker, T., Brookes, K. \& Doudoukina, O. (1998) The pharmacological assessment of herbal oxytocics used in South African traditional medicine. Biomarkers and Environment 2: 42-45.

WHO (2008) Factsheet 134: Traditional Medicine. World Health Organiza, Geneva. 